\title{
GÊNEROS E SEXUALIDADES PRATICADOS EM CURRÍCULOS DISSIDENTES NOS/COM OS COTIDIANOS ESCOLARES ${ }^{1}$
}

\author{
Maria da Conceição Silva Soares \\ Vanessa Maia Bardosa de Paiva \\ Leonardo Nolasco-Silva ${ }^{(*)}$
}

Gritos e lágrimas: afásica enunciação daquilo que sobrevém sem que se saiba de onde Michel de Certeau

\section{Muita careta pra engolir a transação. E a gente tá engolindo cada sapo no caminho. E a gente vai se amando que, também, sem um carinho. Ninguém segura esse rojão Chico Buarque}

Este é um texto sobre ideias que gravitam entre nós, espalham-se nas redes sociais online, adentram as escolas e as universidades, movimentam os grupos de família no Whatsapp e dão o tom das discussões acaloradas e dicotômicas do nosso dia a dia. É um texto que enxerga o perigo sem deixar de olhar para aquilo que o enfrenta, afronta, desafia e inviabiliza. Aqui, para além das interdições que tentam nos impor, nos mais diversos campos quando o tema é corpo, gênero e sexualidade, falaremos de currículos dissidentes, de iniciativas potentes que oportunizam trincheiras teórico-práticas - trincheiras políticas, estéticas, éticas e táticas. Sendo assim, este não é um texto sobre o Programa Escola "sem" Partido, transformado em Projeto de Lei número 867, de $2015^{2}$ que tramita no Congresso Nacional propondo alterações à Lei de Diretrizes e Bases da Educação, mas sobre ideias que, por variadas razões, compõem a sua base.

Se este texto fosse uma música seria Meu Caro Amigo, de Chico Buarque - aquela que mandava notícias numa fita porque o correio andava arisco e a tarifa de telefone não tinha graça. Se na música, Chico contava que a coisa aqui estava preta, neste texto abrimos mão da expressão

\footnotetext{
${ }^{1}$ Uma versão deste texto foi apresentada como trabalho encomendado na $38^{\text {a }}$ Reunião Nacional da Anped, realizada em São Luiz do Maranhão entre os dias 01 e 05 de outubro de 2017.

${ }^{(*)}$ Maria da Conceição Silva Soares. Professora da Faculdade de Educação e do Programa de Pós-graduação em Educação (Proped) na Universidade do Estado do Rio de Janeiro (UERJ). Coordenadora do Grupo de Pesquisa CNPq Currículos, Narrativas Audiovisuais e Diferença.E-mail: ceicavix@gmail.com.

Vanessa Maia Bardosa de Paiva. Professora do Curso de Comunicação Sociial do Departameto de Letras, Artes e Cultura da Universidade Federal de São João del-Rei. Pesquisadora do Grupo de Pesquisa CNPq Currículos, Narrativas Audiovisuais e Diferença. E-mail: vanesssamaia@gmail.com.

Leonardo Nolasco-Silva. Professor da Faculdade de Educação da Universidade do Estado do Rio de Janeiro (UERJ). Pesquisador do Grupo de Pesquisa CNPq Currículos, Narrativas Audiovisuais e Diferença. E-mail: leonolascosilva @gmail.com.

${ }^{2}$ Disponível em: 〈http://www.camara.gov.br/sileg/integras/1317168.pdf>. Acesso em: 25 de julho de 2017.
} 
racista para dizer que continua tudo muito mal, e que precisamos de muita mutreta pra levar a transação. Mas a gente vai levando, só de birra, só de sarro.

Nesta fita, caro amigo, que é texto-manifesto e registro de uma história do tempo presente, falamos daquilo que atravessa os nossos smartphones, notícias que chegam nas muitas noites insones e que vão constituindo um mundo a nossa volta com efeitos devastadores, ainda que disfarçados de memes e emoldurados em telas pretensamente democráticas onde todos tem voz... $\mathrm{E}$ falam demais por não terem nada a dizer. E como dizem!

Dizem, por exemplo, que Enquanto o sono não vem, livro de contos de José Brant, foi recolhido pelo Ministério da Educação (MEC), mesmo tendo sido aprovado pelo Plano Nacional do Livro Didático (PNLD) ${ }^{3}$. Noventa e oito mil exemplares foram retirados das escolas a pedido do Ministro Mendonça Filho porque alguém entendeu que o conto A triste história de Eredegalda era inapropriado para crianças. O conto, que trata do incesto, apresentava um Rei que queria casar com uma das filhas e, diante da recusa dela, castiga-a, fazendo-a morrer de sede. No Brasil, os estupros de vulneráveis são cometidos primordialmente por pais, padrastos e outros parentes próximos e tais crimes demoram a ser publicizados porque na maioria das vezes as crianças não entendem que estão sendo violentadas. Quando se percebem nesta situação encontram resistência dentro de casa e sua palavra é colocada em dúvida (NOLASCO-SILVA, 2006). Abusos sexuais não são, pois, invenções dos contos de fadas. São experiências cotidianas que precisam ser problematizadas nas escolas mas nas escolas um dia chove, noutro dia bate sol.

Aqui na Terra estão jogando futebol - mas os times femininos são menosprezados, ainda que tenhamos a maior jogadora de todos os tempos. Questão de gênero, obviamente, que, também deverá ficar de fora dos assuntos apropriados para as salas de aula, assim como os conflitos gerados pela perseguição às sexualidades divergentes. Diz o portal de notícias ${ }^{4}$ que o MEC cortou a homofobia da lista de preconceitos que devem ser combatidos na Educação. Na terceira versão da Base Nacional Comum Curricular ${ }^{5}$, que redefine os objetivos educacionais para o ensino infantil e fundamental e que foi entregue em abril deste ano de 2017 ao Conselho Nacional de Educação (CNE), trechos que na versão anterior, entregue aos jornalistas dois dias antes ${ }^{6}$, defendiam a

\footnotetext{
${ }^{3}$ Disponível em: <https://brasil.elpais.com/brasil/2017/06/17/opinion/1497719992_556182.html>. Acesso em: 26/07/17.

${ }^{4}$ Jornal DCM, disponível em: <http://www.diariodocentrodomundo.com.br/essencial/mec-corta-homofobia-da-lista-depreconceitos-a-ser-combatidos-com-a-educacao>. Acesso em 15 de julho de 2017.

${ }^{5}$ Disponível em: <http://basenacionalcomum.mec.gov.br/images/BNCC_publicacao.pdf>. Acesso em 23 de julho de 2017.

${ }^{6}$ Conforme notícia publicada na Folha de São Paulo Disponível em: <http://www1.folha.uol.com.br/educacao/ 2017/04/1873366-ministerio-tira-identidade-de-genero-e-orientacao-sexual-da-base-curricular.shtml >. Acesso em 24 de junho de 2017.
} 
necessidade de respeito à "identidade de gênero" e à "orientação sexual" foram sumariamente apagados. Tal ação foi duramente criticada na Revisão Periódica Universal da Organização das Nações Unidas (ONU, 2017) ${ }^{7}$, documento que avalia os países-membro em questões ligadas aos Direitos Humanos. Diz o documento: “A medida fere os princípios básicos da Educação, que garante a igualdade entre os alunos" (s/p).

Mas a gente vai levando, de teimoso, de pirraça e a tela do celular, em meio a tantas desgraças, nos informa que o Ministro Luís Roberto Barroso suspendeu, via $\mathrm{STF}^{8}$, parte da lei (Lei 3.468/2015) que pró́be o ensino de gênero nas escolas. A decisão tem caráter liminar e precisa passar no plenário do Supremo, mas ratifica que tal proibição - levada a cabo no município de Paranaguá, Paraná, viola o princípio constitucional da proteção integral da criança e do adolescente. A lei municipal tenta proibir, inclusive, o uso de termos relacionados a gênero e sexualidade, avançando em uma seara jurídica que é da competência da União - aquela que rege as normas gerais do ensino. Para Barroso, a citada lei "contribui para a desinformação das crianças e dos jovens a respeito de tais temas, para a perpetuação de estigmas e do sofrimento que deles decorre" (Portal O Globo, 2017, s/p. ${ }^{9}$ ).

\section{Meu caro amigo, eu não pretendo provocar...}

É possível que o leitor, nosso caro amigo, não esteja entendendo porque estamos escrevendo como quem apresenta prints de uma timeline qualquer. Mas vamos explicar: precisamos situar a nossa escrita em um movimento incessante de notícias que nos chegam, nos invadem, nos tomam, nos tiram do lugar e nos obrigam a pensar tudo de novo, a rever conceitos. Queremos falar de tentativas de controle dos currículos - e da vida nas escolas - e das resistências, das reinvenções, das dissidências que tais tentativas encontram no caminho. No meio do caminho tinha uma pedra e queremos falar dela: da pedra. Mas também dele: do caminho. A pedra e o caminho que são por muitos - inclusive por nós - desconhecidos, ainda que tenhamos a impressão de estarmos diante de um museu de velhas novidades.

O conquistador burguês se transforma em homem 'fora de si' [...] Fica como um louco. Sonha, tem pesadelos. Perde as suas certezas. Sente-se abandonado por suas razões. Desalojado da

\footnotetext{
${ }^{7}$ Conforme portal da Confederação Nacional dos Trabalhadores em Estabelecimentos de Ensino. Disponível em: <http://contee.org.br/contee/index.php/2017/06/retirada-dos-termos-genero-e-orientacao-sexual-da-base-e-criticada-naonu/>. Acesso em 16 de junho de 2017.

8 Disponível em: <https://oglobo.globo.com/sociedade/stf-suspende-lei-que-proibia-ensino-sobre-genero-nas-escolasdo-parana-21491015>. Acesso em 26/07/17.

${ }^{9}$ Disponível em <https://oglobo.globo.com/sociedade/stf-suspende-lei-que-proibia-ensino-sobre-genero-nas-escolas-doparana-21491015>. Acesso em 24 de julho de 2017.
} 
ascese produtora que lhe garantia o sentido, conhece dias e dias diabólicos, possuído pelo desejo antropofágico de devorar o desconhecido ou pelo temor mesmo de ser devorado (CERTEAU, 2007, p. 24).

O temor, o desprezo, a rejeição e o ódio ao que nos provoca, nos desestabiliza, ao que não se deixa aprisionar e conhecer, pondo em cheque nossas certezas, tem tornado os dias difíceis nas instituições de ensino em que trabalhamos. Tais sentimentos negativos se consubstancializam, quase sempre, em ameaças que querem amedrontar, calar, insistindo em intimidar quem escapa, difere, destoa, quem opta por resistir às subjetividades e à moral burguesa. Ameaças que se atualizam diariamente contra os que não se dobram, não se subordinam, não se deixam enquadrar. Essas ameaças atendem por muitos nomes: censura, mordaça, processo, denúncia, intimidação, assédio, disciplinarização, normalização, cura. Entretanto, as ameaças têm efeitos ambivalentes, lembrando o texto de Certeau (2007) que trouxemos acima: ou ela será eficaz no seu feito de modelar culturas e pessoas a partir de uma única fôrma-molde, ou será devorada, atualizando seu medo fundante. E se a gente tá engolindo uns sapos no caminho, a gente também faz pirueta pra cavar o ganha-pão.

Existe, então, uma cultura de violência que tem oscilado entre a pulsão de devorar e o terror de ser comido (CERTEAU, 2007, p. 248). Nos dias em que estamos vivendo, esse pressuposto de violência habita as falas, programas eleitorais difundidos pela televisão, discursos e projetos político-religiosos que vociferam e transbordam moralidades nos documentos oficiais sobre educação em um país que deveria ser laico. Este embate entre uma almejada laicidade do Estado e seus projetos educacionais e os discursos de um 'Deus-Judeu-Cristão' (CERTEAU, 2007) vem se realizando há muito sem que dediquemos um tempo para pensar na pergunta que o autor nos faz, logo após dizer que o discurso não tem corpo porque “[...] seus herdeiros fazem uma triagem: o novo deus escreve, mas não fala; é autor” (CERTEAU, 2007, p. 251). Essa 'autoria' da qual falamos - sem citar ainda sua razão (anti)social - se distribui em uma legião de pessoas que reúne, em acordos dos mais estranhos, sujeitos que vão desde advogados, passando por ativistas cheios de ódio em páginas de redes sociais, humoristas, líderes religiosos e outros praticantes alçados, sabe-se lá por quem, ao posto de analistas políticos e defensores da moral. Assim sendo, “[...] quem fala? E para quem?" (CERTEAU, 2007, p. 251). Nós, por exemplo, não podemos nos furtar de lhe contar as novidades e queremos fazer isso por meio da ciência, que é a nossa forma de falar no mundo uma forma que participa da disputa pela institucionalização da verdade.

A produção destas retóricas, de acordo com Certeau, pretende fazer das palavras instrumentos para influenciar o querer do outro. Pretende estabelecer adesões e contratos, coordenar 
e modificar práticas sociais e, portanto, forjar a história (CERTEAU, 2007). Estamos vivendo uma ofensiva conservadora na educação que tem como principal alvo o professor e seu papel de educador. Assim, criamos teorias porque também estamos aflitos pra fazer você ficar a par de tudo que se passa.

O que se passa é que estamos escrevendo e atuando em um cenário proibitivo que toma conta da educação e que faz parte de um movimento conservador mais amplo. De algum modo, há algum tempo, fomos deixando de lado tal percepção do perigo e ele foi crescendo, ampliando suas vozes e seus tentáculos e, por mais inconstitucional que ele possa aparentar já não podemos ignorar a força de um discurso moralizante que circula, se revestindo, mais uma vez, de neutralidade e verdade, em toda sociedade, e também nos cotidianos das escolas. Não podemos ignorar tudo aquilo que este discurso condena e exclui.

Esse discurso utiliza-se de uma linguagem próxima a do senso comum, recorrendo a dicotomias simplistas que reduzem questões complexas a falsas alternativas e valendo-se de polarizações já existentes no campo político para introduzi-las e reforça-las no campo educacional. Os memes, imagens acompanhadas de breves dizeres, tem uma grande importância nesse discurso simplista. (PENNA, 2017, p. 35).

Estamos diante de uma contenda pela opinião pública e, até aqui, corremos um sério risco de perder a disputa narrativa. Contra tudo o que julgamos oportuno defender existe uma máquina poderosa de produção diária de discursos, com capilaridade incontestável. O clima de desagregação social que caracteriza o Brasil de hoje cria o cenário propício para a gestação do ódio ao que é tomado como diferença, isto é, o negativo da identidade-padrão socialmente construída e legitimada, que produz o outro como inimigo em potencial que precisa ser vencido antes mesmo de representar algum risco. A burguesia brasileira que historicamente produziu-se antipovo e antinação mostra-se também agora, mais claramente, antidireito universal à escola pública, subordinando-se, sem maiores reservas, aos centros hegemônicos do capital (FRIGOTTO, 2017). A educação deixa de ser uma questão de direito assegurado pelo Estado e passa a ser um produto colocado à venda no mercado e, como tal, gerenciável pelo Código de Defesa do Consumidor - documento que serviu de inspiração ao programa Escola "sem" Partido.

O Escola "sem" Partido não é um discurso novo, tampouco isolado. Suas origens datam de 2004 e são, em teoria, uma reação a um professor de História que teria feito uma comparação entre Che Guevara e São Francisco de Assis. Na turma deste professor estava a filha do Procurador do Estado de São Paulo Miguel Nagib e foi ele quem idealizou este movimento "100\% apartidário" que "tem dois objetivos: combater o uso do sistema educacional para fins políticos, ideológicos e 
partidários e defender o direito dos pais dos alunos sobre a educação moral de seus filhos" (BÁRBARA; CUNHA; BICALHO, 2017, p.106).

Antes de entrarmos mais detalhadamente nas ideias que sustentam tal projeto, precisamos compreender algo do cenário que o abriga. Precisamos entender que ele não coloca em risco apenas a escola pública, laica e republicana, mas também o convívio social, pois se vale de argumentos discriminatórios que, pouco a pouco, sedimentam as relações sociais no dentrofora ${ }^{10}$ das escolas.

Há nele um sentido ideológico e político que potencializa a intolerância aos movimentos sociais e tenta impedir os avanços das lutas populares e da classe trabalhadora. Para tanto, conta com o poderoso auxílio da grande mídia e do crescente mercado de seitas religiosas que usam “deus" como mercadoria, tornando reféns de uma manipulação em cascata um número cada vez maior de pessoas. Versões da realidade são produzidas e veiculadas na TV, nos jornais e na Internet, eficientemente orquestradas pelos interesses de uma elite econômica, dando origem a um fenômeno que tem sido chamado de pós-verdade ${ }^{11}$.

De acordo com Frigotto (2017) o ambiente que propicia o fortalecimento das ideias do Escola "sem" Partido é marcado pela tentativa de interromper duas conquistas dos movimentos sociais: a Constituição de 1988 e a eleição de Luís Inácio Lula da Silva, em 2002. Se a Constituição de 1988 ampliou direitos sociais e subjetivos de forma significativa, garantindo o direito universal à educação básica, a eleição de Lula da Silva representou a possibilidade de consolidação dos avanços constitucionais - quase vinte universidades públicas foram criadas, além de centenas de Institutos Federais de Educação, Ciência e Tecnologia; aumento real do salário mínimo; política de cotas; bolsa família; liberdade de organização para os movimentos sociais e culturais; mudanças substanciais nas relações exteriores, incluindo a participação do Brasil no BRICS ${ }^{12}$. Este conjunto de ações e de mudanças, na visão do autor, tornou-se insuportável para a classe dominante brasileira

\footnotetext{
${ }^{10}$ Nos valemos desse modo de escrever alguns termos juntos e em itálico nas pesquisas nos/com os cotidianos para indicar que o modo dicotomizado de criar conhecimentos que se tornou hegemônico na Ciência moderna tem significado limites ao desenvolvimento das pesquisas nessa corrente de pensamento.

${ }^{11}$ O termo pós-verdade (post-truth) foi eleito a palavra do ano de 2016, pela Oxford Dictionaries. Trata-se, de acordo com o dicionário, de um substantivo "que se relaciona ou denota circunstâncias nas quais fatos objetivos têm menos influência em moldar a opinião pública do que apelos à emoção e a crenças pessoais". Segundo a Oxford Dictionaries, o termo "pós-verdade" com a definição atual foi usado pela primeira vez em 1992 pelo dramaturgo sérvio-americano Steve Tesich. Ele tem sido empregado com alguma constância há cerca de uma década, mas houve um pico de uso da palavra, que cresceu 2.000\% em 2016. Disponível em: <https://www.nexojornal.com.br/expresso/2016/11/16/O-que$\% \mathrm{C} 3 \% \mathrm{~A} 9-\% \mathrm{E} 2 \% 80 \% 98 \mathrm{p} \% \mathrm{C} 3 \% \mathrm{~B} 3 \mathrm{~s}$-verdade $\% \mathrm{E} 2 \% 80 \% 99$-a-palavra-do-ano-segundo-a-Universidade-de-Oxford>. Acesso em: 26/07/17.

12 Abreviatura do bloco econômico formado por países economicamente emergentes: Brasil, Rússia, Índia, China e África do Sul.
} 
e desdobrou-se nos procedimentos do golpe de 31 de agosto de 2016 - um golpe mais profundo e letal que o golpe empresarial-militar de 1964, estando a classe dominante, no cenário atual, organizada como tal no coração do Estado e na sociedade civil.

A produção de verdades ganha respaldos jurídicos com a Operação Lava-Jato ${ }^{13}$ que, entre muitos artifícios, elege uma visão moralista da corrupção para montar um constante Estado Policial, onde tudo é permitido para se garantir a ordem. A exaltação das delações premiadas, em forte associação com as práticas cristãs da culpa e do arrependimento, ajudam a compor o solo estrutural do Escola "sem" Partido que, em sua página na Internet ${ }^{14}$, chega a oferecer um canal para que pais e estudantes denunciem professores-suspeitos de avançarem nos temas proibidos, ultrapassando os limites de sua função instrucionista. O professor, nessa visão, é instrutor e não educador. Há, portanto, uma relação orgânica entre as teses conservadoras do referido programa com os caminhos políticos percebidos no Brasil, sendo o moralismo religioso um importante amálgama dessa mistura.

De acordo com Fernando Penna ${ }^{15}$, professor da Universidade Federal Fluminense (2017), estudioso do assunto, o nome escola "sem" partido já traz em si um auto-engano. Ele prefere, por isso, usar o termo escola sem educação. Para tanto, vale-se dos documentos e vídeos que disseminam pelo país as teses do projeto, todas elas reducionistas e desconhecedoras da realidade da educação e da complexidade da escola. A saber: a) reduz o papel do professor a um mero transmissor de conhecimento; b) reduz o papel do aluno ao papel de consumidor e c) reduz a relação educacional a uma relação comercial baseada no código de defesa do consumidor.

O programa, que se auto intitula "apartidário", tem suas garras fincadas em associações político-partidárias muito bem definidas. Trata-se de "uma poderosa teia de relações que surpreende pelo cunho conservador, com várias articulações e redes que perpassam por entidades da sociedade civil, instâncias religiosas e partidos políticos" (ESPINOSA; QUEIROZ, 2017, p. 49). No Rio de Janeiro, por exemplo, ele surgiu na cena legislativa por iniciativa do deputado estadual Flávio Bolsonaro, do Partido Social Cristão (PSC). A partir de então, o projeto foi disponibilizado para todo o país como um anteprojeto de lei que poderia ser utilizado por estados e municípios, bastando que, para isso, os representantes (vereadores e deputados) o apresentassem em suas cidades e

\footnotetext{
${ }^{13}$ Nome dado a uma operação de investigação iniciada em 2014 pelo Ministério Público Federal que investiga desvio e lavagem de dinheiro. Fonte: <http://lavajato.mpf.mp.br/>.

${ }^{14}$ Disp.: <http://www.programaescolasempartido.org/>.

15 Todos os dados e informações sobre o Escola "Sem" Partido foram retirados da palestra do professor Fernando Penna (UFF/RJ) no Congresso do Andes, realizado na UFES/ES, em Vitória no dia 05 de abril de 2017.
} 
estados. Projeto análogo também tramita no Congresso Nacional e, no estado de Alagoas, já se tornou lei, apresentado com o nome "Escola Livre" (PENNA, 2017).

No cenário educacional idealizado pelo Escola "sem" Partido o professor não pode mencionar o noticiário político local, nacional ou internacional. O professor não deve ater-se ao evolucionismo, precisa também falar de Adão e Eva e, por fim o professor não pode falar de gênero. Nessa perspectiva, o professor se tornaria um mero instrutor, alguém destinado ao exercício da burocracia (PENNA, 2017). A defesa do professor como burocrata foi apresentada em um vídeo no qual o advogado Miguel Nagib diz:

[...] Burocrata não faz sermão. O burocrata aplica a lei. Pune. Exige o cumprimento da norma. Quem diz o que é moral e o que é imoral é padre, é pastor, é pai, é mãe. Não é o funcionário público. O funcionário público só faz o que a lei determina e a lei brasileira não possui um decálogo, não possui um código moral. Quem possui código moral são as religiões. Burocrata não faz sermão. Burocrata transmite aos alunos o conteúdo do currículo, aquilo que está escrito, aprovado pelas autoridades competentes. Não lhe cabe dizer aos filhos dos outros o que é certo, o que é errado. ${ }^{16}$

O Escola "sem” Partido não só disponibiliza projetos de lei para que sejam adotados por todo o país, mas indica em seu site uma série de livros que embasam as ideias do professor como instrutor e ainda ensina a fazer 'denúncias' de professores que, por ventura, estejam contrariando o projeto. O tom do site é policialesco.

No lado direito (Figura 1) do site existem links com 'orientações' como Cartaz com deveres

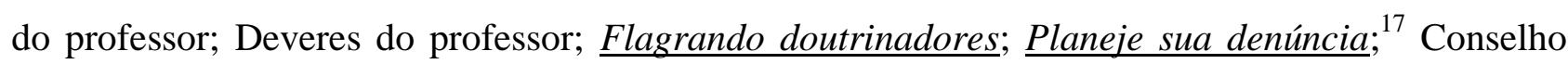
aos pais; Caso COC. Ainda no mesmo site, do lado esquerdo, existe uma lista denominada Biblioteca Politicamente Incorreta, na qual constam livros como Por uma Geografia Crítica e Guia Politicamente Incorreto da História do Brasil e, ainda, abas com os dizeres "corpo de delito", “defenda seu filho" e “a doutrinação pelo mundo", “os livros didáticos” (Figura 2).

\footnotetext{
${ }^{16}$ Vídeo captado em uma audiência pública, na qual compareceu o idealizador do projeto Escola "sem" Partido, apresentado pelo professor Fernando Penna (UFF/RJ) em palestra no Congresso Andes, realizado em Vitória em 05 de abril de 2017.

${ }^{17}$ Grifos nossos.
} 


\section{FIGURA 1}

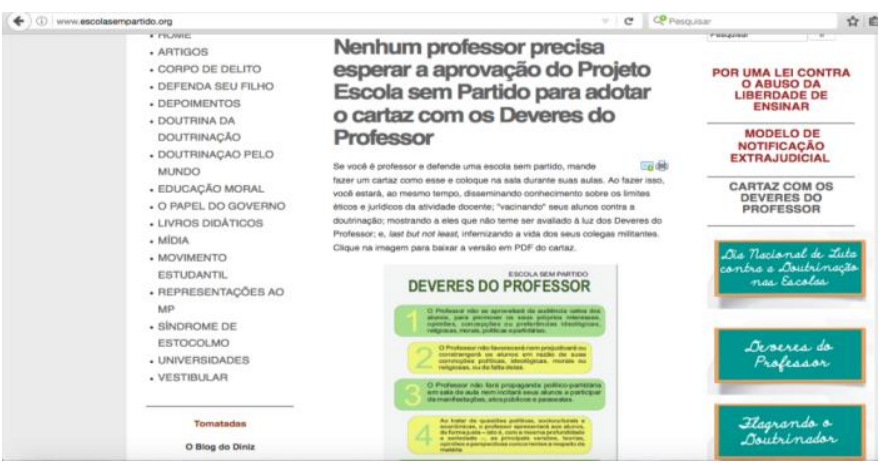

FIGURA 2.

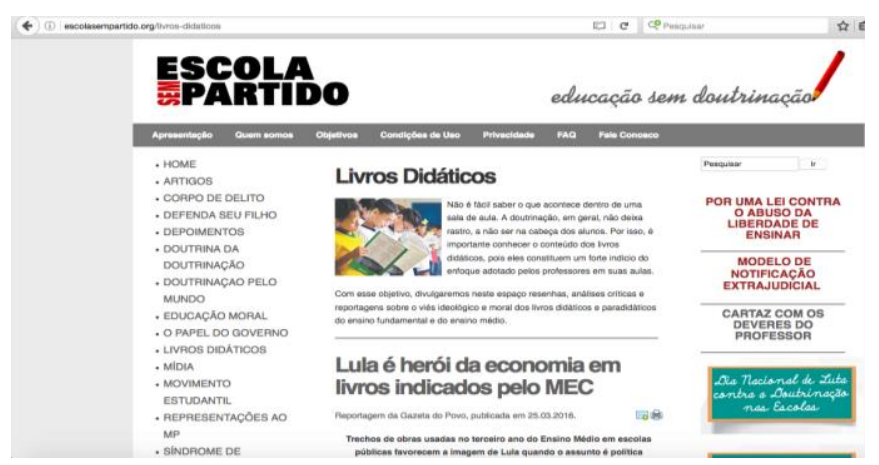

A campanha de desvalorização da carreira docente, que transforma o professor em burocrata e transmissor, é nítida, agressiva e articulada. O site Escola "sem” Partido já gerou outros produtos comunicacionais para interagir e conquistar adesão de quem não entende muito ou não está disposto a problematizar o tema. A rede social Facebook está repleta de páginas que 'viralizam' as ideias defendidas por esse grupo (Figuras 3 e 4).

\section{FIGURA 3.}

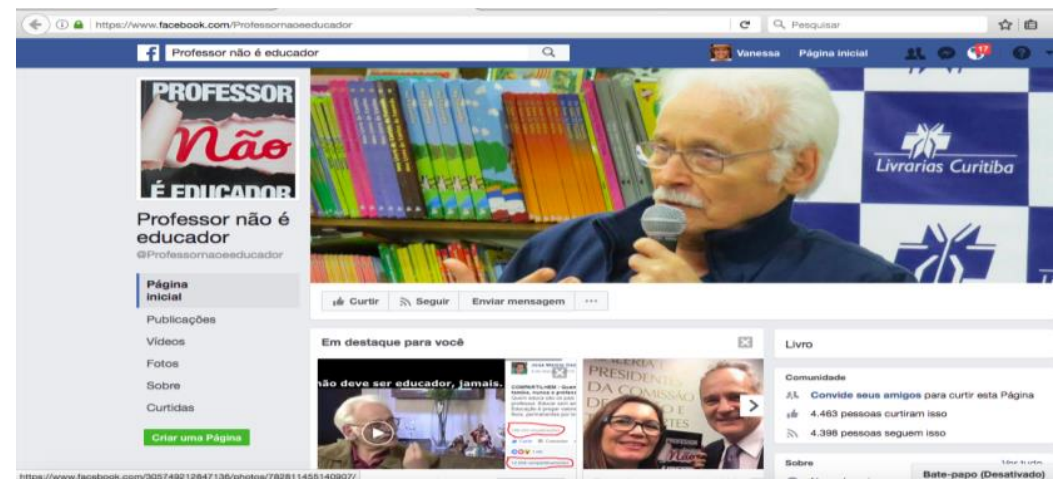




\section{FIGURA 4.}

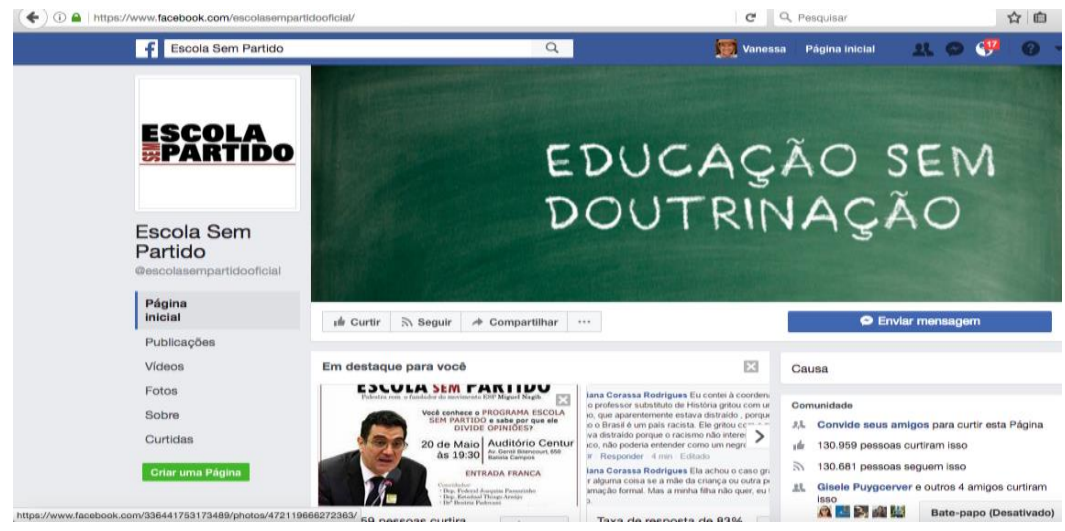

Mas o que tanto ameaça? Por que professores e estudantes não podem falar de suas formações, de seus desejos, de como viver em um mundo com tanta desabitação da vida? Do que têm medo os idealizadores do Escola "sem" Partido? Apostamos com Certeau (2007) que têm medo de serem "devorados". Por isso, necessitam, precisam, devorar o desconhecido. "Quem articula o poder, sabe-se cada vez menos como poderia falar" (CERTEAU, 2007, p. 252). Por isso o tom policialesco da página, a intimidação da multiplicidade de vozes e de corpos que habitam os cotidianos das escolas.

De acordo com Fernando Penna os ideólogos do Escola "sem" Partido subverteram o slogan do feminismo, "meu corpo, minhas regras", para "meus filhos, minhas regras". A escola, na avaliação daqueles defensores, estaria usurpando a autoridade dos pais. Usam, segundo exemplo utilizado por Penna, uma imagem compartilhada de uma família - um homem, uma mulher e duas crianças - usando um guarda-chuva que os estaria 'protegendo' contra uma chuva com as cores do arco-íris, numa alusão clara ao símbolo indicativo do movimento LGBTT $^{18}$ (figura 5). Que concepção é essa?

\section{FIGURA 5.}

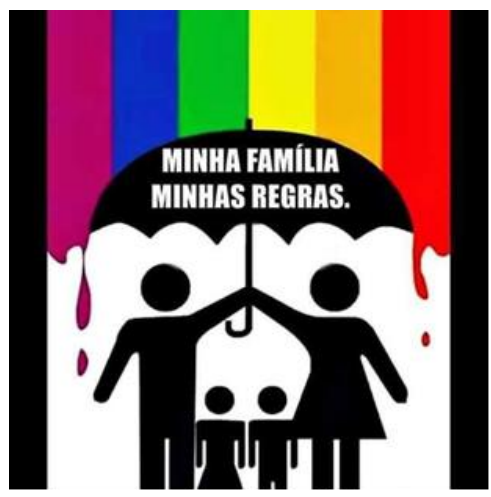

\footnotetext{
${ }^{18}$ Disponível em: <https://br.pinterest.com/pin/325877723019049697/>. Acesso em 02/07/2017.
} 
Visitando a página do movimento Escola "sem" Partido ${ }^{19}$ são inúmeras as fotos e cartazes depreciativos contra todo o trabalho que vem sendo arduamente praticado nos cotidianos das escolas para combater o preconceito. Valem-se do termo "Ideologia de Gênero" para desqualificar a discussão de gênero nas escolas. Eles dizem que é uma ideologia antifamília. Entendem as discussões de gênero como uma tentativa de transformar as crianças em gays, lésbicas e trans. Quando, na verdade, discutir gênero tem a ver com combater preconceito, homofobia, lesbofobia, transfobia etc.

Quando os pais se opõem (e buscam controlar a autonomia da escola e do docente) a discutir na sala de aula temas que fazem parte do mundo em que seus filhos vivem e sobre o qual se indagam, como homossexualidade, aborto, transexualidade, estão, na verdade, se contrapondo a uma formação para a contemporaneidade, em que o direito à diferença, em suas múltiplas expressões, constitui dimensão inerente à cidadania. Os pais estão também assumindo uma posição obscurantista, de negação de acesso a uma informação e debate mais qualificados. Tais temas já se fazem presentes o tempo todo na vida destas crianças e adolescentes: nas mídias, nas ruas, nos discursos e nos corpos de figuras públicas. É natural que se interroguem e é dever da escola debate-los de forma responsável e consistente. (GOUVEA, 2017, s/p).

\section{A GENTE VAI LEVANDO DE TEIMOSO E DE PIRRAÇA...}

Como diz a canção que nos serve de inspiração neste texto-em-movimento, a gente vai cavando só de birra, só de sarro e as tentativas de cerceamento nos dão força para criar espaçostempos de liberdade. Partindo da afirmação foucaultiana que fala da liberdade como intransitiva, isto é, o que vem antes, desejamos falar sobre os atos de produção de currículos para além das determinações e fixações político-institucionais.

Currículos, conforme compreendemos nas pesquisas nos/com os cotidianos, são espaçostempos de encontros entre diferenças, de reconhecimento e estranhamento, de escrituras sobrepostas, práticas negociadas, bricoladas e abertas à invenção, às contingências e às oportunidades. São atos coletivos, criados cotidianamente nas escolas, mesmo que em sua origem encontremos arbitrariedades políticas e teóricas e tentativas de controle. Currículos são declarações de intenções institucionais, produtos de políticas públicas e decisões administrativas. Mas são ainda derivações de corpos, mimeses de gestos, produção de desejos, inventividades e resistências daqueles que habitam os temposespaços escolares, com suas presenças - físicas e virtuais -, ausências, temporalidades, astúcias, confrontos, enfim, com aquilo que não tem governo, nem nunca terá.

\footnotetext{
${ }^{19}$ Disponível em: https://www.facebook.com/pg/escolasempartidooficial/photos/?ref=page_internal. Acesso: 02/07/17.
} 
Os currículos praticados nas escolas são tecidos em redes, no entrelaçamento de saberesfazeres criados nos múltiplos contextos em que vivemos e aprendemos, entre eles as teorias educacionais, as políticas públicas, os usos das mídias, os dogmas religiosos, a experiência comunitária, a fruição das artes, a experiência com os movimento sociais e as potências e os prazeres dos corpos. Nessa perspectiva, independente das leis e das autoridades, os gêneros e a sexualidade estão no cotidiano das escolas e, como indicam nossas pesquisas, debater tais temas é uma demanda permanente dos estudantes. Conforme sugere Soares (2009, p. 178):

A questão da sexualidade, pensada por Foucault como política do sexo, mas também como estética de existência, está presente em múltiplas redes de relações cotidianas nas escolas: nas reivindicações manifestadas nas falas de alunos e professores; nas trocas de confidências na hora do recreio e da entrada; nos insultos e agressões em meio às brigas por outros motivos quaisquer; nas práticas de alunos dentro e fora das escolas que são comunicadas aos pais e resultam em suspensões ou que viram lendas, boatos e fofocas que povoam corredores e salas de aula; na utilização das quadras esportivas; no acesso a atividades extra-sala, como as aulas de dança e futebol; nos livros didáticos; nos trabalhos e cartazes; nas apresentações realizadas por alunos nas festas; e na insistência em usar shorts curtos e roupas diferentes e sexys, entre outras coisas. É, portanto, uma questão que, independente de qualquer prescrição da SEME ou deliberação da escola, faz parte do currículo.

FIGURA 6.

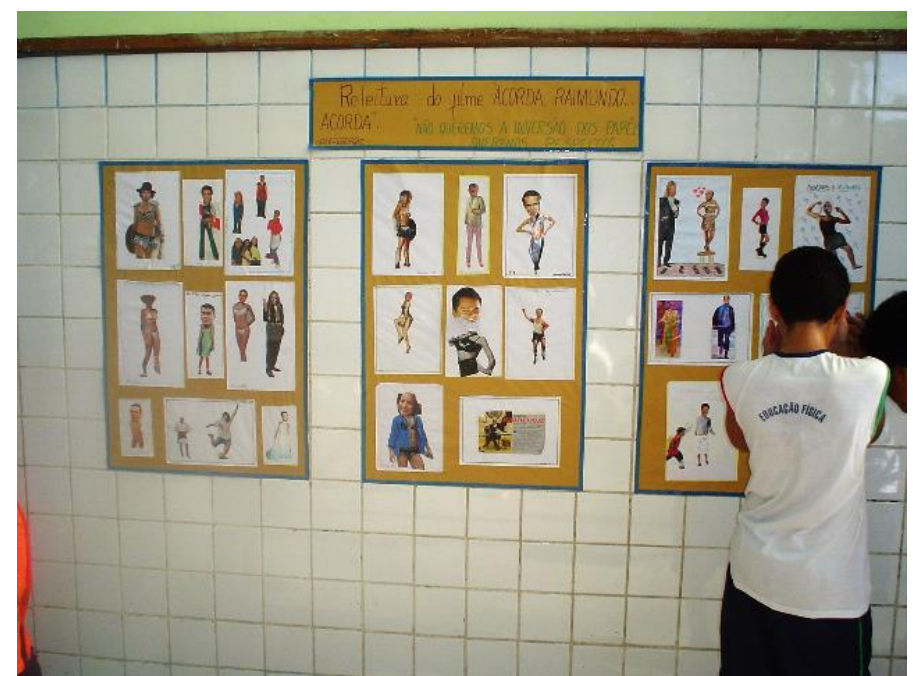

Trabalho escolar em mural feito com colagens para problematizar os estereótipos de gênero, a partir do filme Acorda Raimundo, realizado por estudantes de uma escola municipal de ensino fundamental da Rede Pública de Vitória, em 2005.

Assim como os currículos, buscamos com nossas pesquisas pensar também os corposgêneros-sexualidades praticados nos/com os cotidianos das escolas e o que eles produzem: disciplinam e/ou instituem espaços de liberdade e experiência? Organizam e/ou desorgarnizam as relações de poder com os usos que fazem do que é recebido ou imposto, isto é, prescrito? O que 
sugerimos é que, ao modo das táticas, que obedecem a uma ordem transgredindo-a (CERTEAU, 2007), os corpos-gênero-sexualidades praticados criam sempre diferenças em relação aos sistemas de referência com as operações de usar-fazer-saber-dizer-atualizar as normas.

Pensar os corpos-gêneros-sexualidades como prática cultural, implica pensar o papel da experiência e da imaginação na produção de sentidos e nas encenações e performances (gestos e rituais) nos processos miméticos que estão na base das aprendizagens práticas para a vida em sociedade (WULF, 2013).

Nossas pesquisas indicam também a presença das discussões sobre corpo-gênerosexualidades nos cotidianos das escolas em vídeos publicados no Youtube. Embora ainda em andamento, uma pesquisa que estamos realizando sobre vídeos produzidos como trabalhos escolares contra a homofobia compartilhados no Youtube, aponta, em uma primeira análise que, independente dos recursos disponibilizados para as escolas e/ou dos projetos pedagógicos, os artefatos tecnológicos e dispositivos de produção de imagens já estão ocupando e modificando os espaçostempos escolares, potencializando outros modos de se narrar e de narrar o mundo, transbordando políticas oficiais e instituindo mais um espaçotempo de discussão sobre gênero e sexualidade nos processos curriculares.

A partir de um levantamento realizado em 2015 e 2016, buscando no site pelas palavras "trabalho" e "homofobia" juntas, encontramos centenas de vídeos produzidos sobre essa temática. Decidimos trabalhar com as primeiras 165 produções encontradas. Fizemos download dos vídeos e os arquivamos em pastas individuais acompanhados de uma ficha com todos os dados que pudemos reunir: data da postagem, do acesso, número de visualizações, comentários, autores, escola, região, tempo de duração etc. Em alguns casos, estamos tentando contato com os realizadores em busca de mais informações. Os vídeos estão sendo analisados pela equipe da pesquisa.

Entre os vídeos já assistidos que indicam os espaçostempos em que foram produzidos, pudemos constatar que a maior parte deles é realizada por estudantes de escolas estaduais de ensino médio, embora haja também trabalhos produzidos por estudantes de escolas particulares e públicas de diferentes níveis de ensino, como em faculdades e dos anos finais do ensino fundamental de várias regiões do país, de capitais e cidades do interior. Entre as disciplinas para as quais os trabalhos foram criados estão Sociologia, Filosofia, Redação, História, Arte, Português, Inglês, Espanhol e Biologia. 
Grande parte dos vídeos visualizados foi produzida a partir de uma composição entre textos e fotografias disponíveis na internet (bandeiras do movimento LGBT e casais gays, por exemplo), com uma música de fundo.

\section{FIGURA 7.}

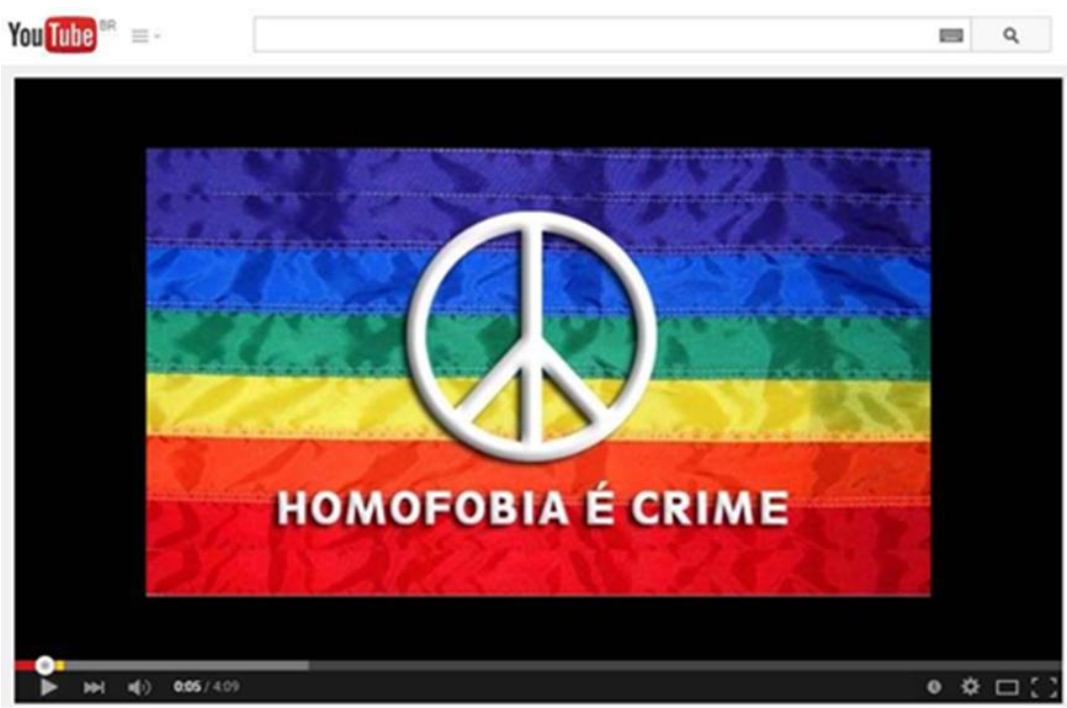

Imagens com a bandeira com as cores do arco-íris e frases condenando a homofobia estão presentes na maior parte dos vídeos produzidos por estudantes e compartilhados no Youtube.

Imagens em movimento também são usadas nos audiovisuais em muitas outras montagens para compor com os textos e fotografias, tais como reportagens de programas jornalísticos que denunciam diferentes tipos de violência contra homossexuais e transexuais, cenas de filmes ficcionais, fragmentos de documentários, peças publicitárias e depoimentos. Os estudantes também protagonizam muitos vídeos, sejam documentários, nos quais estudantes narram suas experiências nas escolas e na família, denunciando o preconceito, ou em ficções, nas quais atuam vivenciando a experiência uns dos outros.

\section{FIGURA 8.}

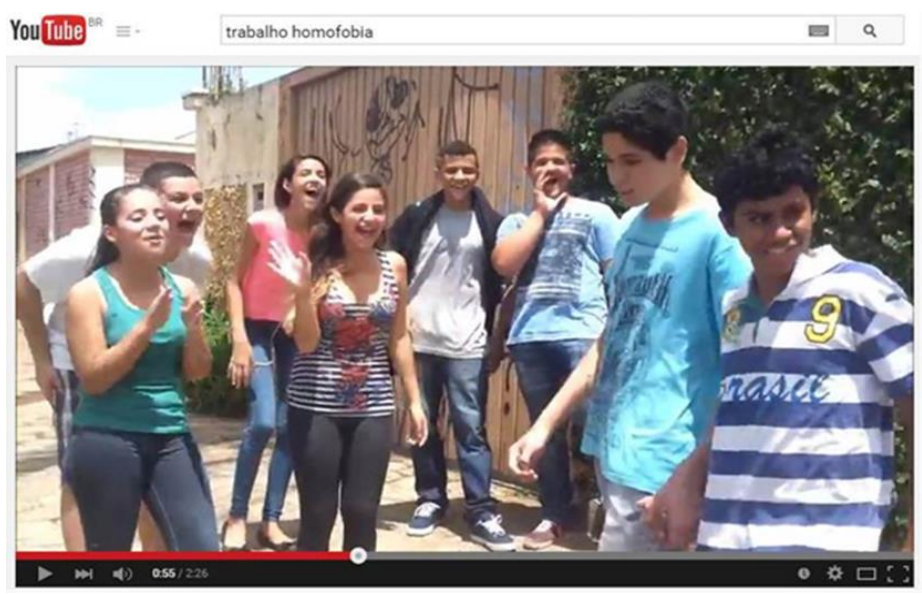

Vídeo de ficção em que estudantes simulam o preconceito e a violência contra um casal de meninos homossexuais. 
Ainda a título de exemplificação, trazemos um acontecimento que nos foi narrado na contingência de uma pesquisa sobre transexualidade e educação, realizada por uma integrante de nosso grupo, quando uma mulher transgênera, entrevistada para a pesquisa, foi questionada sobre as práticas de generificação na escola. Apesar de denunciar segregações e constrangimentos impostos, especialmente no que diz respeito à obrigatoriedade do uniforme e ao uso do banheiro, que são fortes marcadores de gênero e das fronteiras que se impõe com eles, ela referiu-se com entusiasmo às filas separadas para meninos e meninas na entrada e na saída da sala de aula. Diante da imposição em perfilar com os meninos, correspondendo às expectativas construídas em relação ao corpo-sexo-gênero que lhe foram atribuídas, ela nos contou que aproveitava essa situação para "roçar" seu corpo nos corpos dos demais garotos, o que a levava a sentir prazer e produzir desejo. Tal atitude, baseada no apetite de seu corpo, produzia regozijo e potencializava o desengessamento dos corpos, aliás, de todos os corpos.

Essas e outras diferentes práticas que estão nas escolas produzem a diferença sexual ou a desconstroem. Aprendemos e nos formamos em diferentes contextos de nossas vidas cotidianas e levamos conosco nossas redes de conhecimentos, significações e subjetividades quando entramos nas escolas e elas constituem os currículos praticados.

Assim, para pensar e discutir processos curriculares criados nas escolas, precisamos problematizar a ideia de currículo apenas como prescrição e considerar os fragmentos e a complexidade das redes tecidas nos cotidianos escolares nas/pelas/com operações de seus praticantes.

\section{Mas acontece que não posso me furtar...}

Considerando que as práticas cotidianas, informadas por desejos e interesses que não, necessariamente, os hegemônicos, produzem outras coisas com os usos do que é imposto, ampliamos a definição de currículos prescritos para nela sublinharmos as dissidências. Reconhecemos a vontade de poder neles inscritas, mas olhamos para o que deles transborda, escapa, pulsa em atos de indisciplina. E fazemos isso para problematizar a pretensão de cerceamento contida no Programa Escola "sem" partido e na Base Nacional Comum Curricular, indagando seus pressupostos a partir das pesquisas nos/dos/com os cotidianos escolares.

Nos limites deste texto, sublinhamos o debate sobre gênero e sexualidade, reconhecendo o papel central que este tema tem desempenhado nas discussões do citado programa político- 
religioso-empresarial. E, para tanto, trouxemos para o debate a ideia de currículos dissidentes ${ }^{20}$. Assim sendo, as vivências aprendidasensinadas em nossas pesquisas nos/com os cotidianos das escolas protagonizam questões para os currículos, independente das proibições, normatizações e sanções. Currículos dissidentes seriam, a partir da apropriação que estamos fazendo, currículos praticados que contestam destinos pré-determinados a partir de toda ordem, por meio de criações, performatividades, autoapresentações e autorrepresentações que os estudantes e professores fazem/ inventam/atualizam/fabulam a partir do que lhes é imposto como norma.

No entendimento que caminhamos com este texto, de nada adianta proibir o debate sobre gêneros e sexualidades nas escolas porque este se atualiza com a presença de seus praticantes e com as operações produtoras de significações que elas engendram, desafiando o que está sendo recomendado como "o correto". Currículos dissidentes são currículos que se modificam, se redesenham, se performativam, com os usos que seus praticantes fazem dos repertórios que dispõem, apesar das proibições que estão colocadas, transformando esses processos em uma experiência ética-estética-política de se autoapresentar, de se autorrepresentar e de constituir a si próprio e o mundo.

Há na noção de currículos dissidentes algo que perturba a ordem, a norma, a prescrição. E esta prática desestabiliza o que está sendo ditado por agentes conservadores cujas vozes se escutam desde a política até a religião. O que nos interessa ver neste conceito são as possibilidades de contestar, de existir e de criar significações que estão sendo exercidas das mais variadas formas e maneiras nos cotidianos das escolas. Atos que podem significar pouco, para os que só enxergam a homogeneização, mas que subvertem diversas questões, inclusive as fronteiras de gênero e a regulação da sexualidade, criadas com a classificação dos corpos e a normalização dos prazeres, no contexto das relações de poder.

São estes pequenos e contínuos atos de contestação - e de criação de possibilidades outras de pensarpraticar os cotidianos escolares - que ressaltam a presença de currículos dissidentes, produzidos por e produtores de corpos dissidentes que não se deixam capturar por uma subjetivação condizente com interesses do capital e de seus processos de regulação, através da docilização e utilidade. Quando trazemos para este texto as vivências das pesquisas, nas situações que elas nos apresentam, interessamo-nos mais pelos movimentos, pelas criações, pelas táticas e astúcias do que

\footnotetext{
${ }^{20} \mathrm{O}$ conceito dissidente nos é caro e foi tomado por empréstimo por nós da valiosa obra do professor Fernando Pocahy, que o desenvolveu para abordar a questão das sexualidades dissidentes. A fonte é sua tese de doutoramento na Universidade Federal do Rio Grande do Sul, intitulada "Entre vapores e dublagens: dissidências homo/eróticas nas tramas do envelhecimento”, defendida em 2011, sob orientação da professora doutora Guacira Louro.
} 
pela coerência que cada um desses processos poderia produzir. Entendemos que uma norma sempre terá um caráter ambivalente porque, para além do que ela pretende assegurar, também produzirá no seu mesmo movimento, disputas, embates, contestações, criações e, é claro, dissidências.

Vale ressaltar, por fim, que as políticas de Estado para os currículos, assim como as teorias curriculares, constituem parte dos repertórios do imaginário dos praticantes das escolas, a partir dos quais tecem suas redes de saberesfazeres e poderes. Por isso, nossa luta é para que essas diretrizes e políticas contemplem e legitimem o que se cria com as práticas, alargando as possibilidades ao invés de tentar desqualificá-las, interditá-las e reduzi-las.

\section{REFERÊNCIAS}

BÁRBARA, Isabel Scrivano M. Santa; CUNHA, Fabiana L.; BICALHO, Pedro Paulo G.. Escola sem Partido: visibilizando racionalidades, analisando governamentalidades. In: FRIGOTTO, Gaudêncio. (Org.). Escola "sem" Partido. Esfinge que ameaça a educação e a sociedade brasileira. Rio de Janeiro: UERJ/ LPP, 2017. p. 105-120.

CERTEAU, Michel de. A Invenção do Cotidiano: 1. Artes de Fazer. Tradução Ephraim Ferreira Alves, Petrópolis, RJ: Vozes, 2007.

ESPINOSA, Betty R. Solano; QUEIROZ, Felipe B. Campanuci. Breve análise sobre as redes do Escola sem Partido. In: FRIGOTTO, Gaudêncio. (Org.). Escola "sem" Partido. Esfinge que ameaça a educação e a sociedade brasileira. Rio de Janeiro: UERJ/LPP, 2017. p. 49-62.

FRIGOTTO, Gaudêncio. A gênese das teses do Escola sem Partido: esfinge e ovo de serpente que ameaçam a sociedade e a educação. In: FRIGOTTO, Gaudêncio. (Org.). Escola "sem” Partido. Esfinge que ameaça a educação e a sociedade brasileira. Rio de Janeiro: UERJ/LPP, 2017. p. 17-34.

GOUVEA, Maria Cristina S. A Polêmica do Colégio Santo Agostinho e a Educação para o Mundo Contemporâneo. 2017. Pensar a Educação - um jornal para a educação brasileira. Disponível em .https://www.pensaraeducacaoempauta. com/a-polemica-do-colegio-santo-agostin?utm_campaign=452b0ef363EMAIL_CAMPAIGN_2017_07_14\&utm_ medium =email\&utm_source=COORDS.\%2BANPED\&utm_term=0_3ba8b04079-452b0ef363-299629921. Acessado em 18/07/2017.

NOLASCO-SILVA, Leonardo. O público de um crime privado: estupro, masculinidades e condicionantes culturais Apontamentos para Políticas Públicas de reintegração de infratores, prevenção e atendimento a mulheres. Dissertação (Mestrado em Sociologia) - Programa de Pós-Graduação em Políticas Sociais. UENF, 2006.

PENNA, Fernando de Araújo. O Escola sem Partido como chave de leitura do fenômeno educacional. In: FRIGOTTO, Gaudêncio (ORG.). Escola "sem" Partido. Esfinge que ameaça a educação e a sociedade brasileira. Rio de Janeiro: UERJ, LPP, 2017, p. 35-48.

Palestra do professor Fernando Penna (UFF/RJ) no Congresso do Andes, realizado na UFES/ES, em Vitória no dia 05 de abril de 2017.

POCAHY, Fernando. Entre vapores e dublagens: dissidências homo/eróticas nas tramas do envelhecimento. 2011.167 p. Tese (Doutorado em Educação) - Universidade Federal do Rio Grande do Sul, Porto Alegre, 2011.

SOARES, Maria Conceição Silva Soares. A comunicação praticada com o cotidiano da escola. Vitória: Espaço Livros, 2009.

WULF, Christoph. Homo pictor: imaginação, ritual e aprendizado mimético no mundo globalizado. São Paulo: Hedra, 2013. 


\section{RESUMO}

Este artigo problematiza as políticas que atualmente estão em debate a partir do Programa Escola "sem" Partido, transformado em projeto de lei que tramita no Congresso Nacional. O texto trata das atitudes conservadoras que avançam sobre a Educação, desconsiderando a diferença que habita o cotidiano nas/das escolas. Apresenta micropolíticas de resistência que tencionam o poder de pensar a escola a partir dos gabinetes. A partir da metodologia das pesquisas com os cotidianos, apresenta resultados de pesquisas que indicam que não adianta proibir o debate sobre gêneros e sexualidades nas escolas porque este se atualiza com as práticas do dia a dia, desafiando o que está sendo recomendado como "o correto".

Palavras-chaves: Currículos dissidentes; gênero e sexualidade; escola sem partido.

\section{GENDERS AND SEXUALITIES PRACTICED IN DISSIDENT CURRICULUM IN/WITH THE DAILY SCHOOL ACTIVITIES \\ ABSTRACT}

This paper problematizes the policies that are currently under discussion through the project Programa Escola "sem" Partido, transformed into law project that has been in the National Congress. The text talks about the conservative attitudes that moves forward over the Education, disconsidering the difference that exists the daily scholar routine. It introduces micro policies of resistance that stress the ability of thinking school from the offices. From the methodology of researches with the routines, it presents results of researches that show that there is no point in prohibiting the debate about genders and sexualities in schools, because it is updated with the everyday activities, challenging what has been pointed as "correct".

Keywords: Dissident curriculum, gender and sexuality; school without party.

\section{GÉNEROS Y SEXUALIDADES PRACTICADOS EN CURRÍCULOS DISIDENTES EN LOS COTIDIANOS ESCOLARES RESUMEN}

El artículo problematiza las políticas que actualmente están en debate en Brasil a partir del Programa Escuela "sin" Partido, transformándose en un proyecto de ley que actualmente tramita el Congreso Nacional. El texto trata de actitudes conservadoras que avanzan sobre la educación desconsiderando la diferencia que habita en el cotidiano de las escuelas. Problematiza estas iniciativas, presentando micro políticas de resistencia que se enfrentan al poder que piensa la escuela desde los despachos. A partir de la metodología de las investigaciones con los cotidianos, se presentan resultados que indican que no vale de nada prohibir el debate sobre géneros y sexualidades en las escuelas porque este se actualiza con las prácticas del día a día, desafiando lo que se recomienda como "correcto".

Palabras-clave: currículos disidentes; género y sexualidad, escuela sin partido. 